\title{
INVESTIGATION OF TRANSIENT NUCLEATE BOILING PROCESSES AND THEIR PRACTICAL USE IN HEAT TREATING INDUSTRY
}

\author{
Nikolai Kobasko \\ Ltd Intensive Technologies \\ 68/1 Peremohy ave., Kyiv, Ukraine, 03113 \\ nkobasko@gmail.com
}

\begin{abstract}
In the paper transient nucleate boiling process is widely discussed. It's unknown previously and investigated by author characteristics create a basis for designing of new technologies which allow receiving super strengthened materials. Obtained results are also used for appropriate software development to be widely applied for control of technological processes and cooling recipes design. A possibility of transition from real heat transfer coefficients (HTCs) to effective HTCs is discussed in the paper too. It is shown that core temperature of steel parts at the end of transient nucleate boiling (self-regulated thermal process (SRTP)) is a linear function of a part dimension when convective heat transfer coefficient during quenching in liquid media is fixed. Also, it is shown that effective Kondrtajev number $\mathrm{Kn}$ is a function of part size and convection intensity and is almost linear function for large sizes of steel parts. Surface temperature at the beginning of self-regulated thermal process and at its end is calculated depending on size and intensity of cooling. Based on obtained new results, it is possible to design DATABASE for liquid quenchants using standard Inconel 600 probe combined with the Liscic/Petrofer probe. Obtained results can be useful for engineers and software designers.
\end{abstract}

Keywords: SRTP characteristics, core temperature at the end of boiling, DATABASE, standard probes, software.

\section{Introduction}

Nobody knows how to use standard testing data to predict real quenching processes in heat treating industry and develop correctly cooling recipes for steel parts during hardening. It is explained by complicated problem which includes shock boiling, local and developed film boiling, transient nucleate boiling process and convection. Local and full film boiling processes generate four types of heat transfer modes [1,2] which require choosing specific boundary condition to make correctly calculations. It is shown in last decades that any film boiling during quenching is not desirable and it must be eliminated by use:

- optimal concentration of water salt solutions maximizing the first critical heat flux densities;

- hydrodynamics emitters to provide resonance effect which destroys film boiling processes;

- special additives which create insulating surface layer at the surface of steel parts decreasing initial heat flux density;

- vigorous agitation of liquid quenchant to provide direct convection and other possibilities.

Based on experimental data of French (French, 1930) and analytical solutions of hyperbolic heat conductivity equation, one can come to conclusion that film boiling can be absent completely when quenching steel parts in agitated cold liquid media [3].

Let's note that intensive quenching without any film boiling eliminates quench crack formation and decreases distortion [2]. That is why in current paper, it is assumed that film boiling during quenching in liquid media is absent and only transient nucleate boiling and convection take place. Mathematical model for such process is considered below.

\section{Mathematical model for quench process design}

If film boiling is absent and transient nucleate boiling takes place, the mathematical model for cooling process is written as [2, 4]:

$$
\operatorname{c\rho } \frac{\partial \mathrm{T}}{\partial \tau}=\operatorname{div}(\lambda \operatorname{grad} T),
$$




$$
\left[\frac{\partial \mathrm{T}}{\partial \mathrm{r}}+\frac{\beta^{\mathrm{m}}}{\lambda}\left(\mathrm{T}-\mathrm{T}_{\mathrm{S}}\right)^{\mathrm{m}}\right]_{\mathrm{r}=\mathrm{R}}=0
$$

After the transient boiling process is finished, convection starts and the third kind of boundary condition (3) is used instead of boundary condition (2):

$$
\left[\frac{\partial \mathrm{T}}{\partial \mathrm{r}}+\frac{\alpha_{\text {conv }}}{\lambda}\left(\mathrm{T}-\mathrm{T}_{\mathrm{m}}\right)\right]_{\mathrm{r}=\mathrm{R}}=0 .
$$

A transition from nucleate boiling to convection is determined by equalizing the heat fluxes, Eq. (4), i. e.

$$
\mathrm{q}_{\mathrm{nb}} \equiv \mathrm{q}_{\mathrm{conv}} .
$$

Also, initial austenitizing temperature should be added, Eq. (5):

$$
\mathrm{T}(\mathrm{r}, 0)=\mathrm{T}_{0}
$$

Taken into account these facts, authors $[2,5]$ received an analytical solution of heat conductivity equation (1) with the boundary condition (2), (3) and initial condition (4) which allows calculating duration of transient nucleate boiling process, Eq. (6):

$$
\tau_{\mathrm{nb}}=\left[0.24 \mathrm{k}+3.21 \ln \frac{\vartheta_{\mathrm{I}}}{\vartheta_{\mathrm{II}}}\right] \frac{\mathrm{K}}{\mathrm{a}},
$$

where

$$
\vartheta_{\mathrm{I}}=\frac{1}{\beta}\left[\frac{2 \lambda\left(\vartheta_{0}-\vartheta_{\mathrm{I}}\right)}{\mathrm{R}}\right]^{0.3} ; \vartheta_{\mathrm{II}}=\frac{1}{\beta}\left[\alpha_{\text {conv }}\left(\vartheta_{\mathrm{II}}+\vartheta_{\mathrm{uh}}\right)\right]^{0.3} ; \vartheta_{\mathrm{I}}=\mathrm{T}_{1}-\mathrm{T}_{\mathrm{s}},
$$

$\mathrm{T}$ is temperature, $\mathrm{T}_{\mathrm{o}}$ is initial temperature, $\mathrm{T}_{\mathrm{m}}$ is bath temperature, $\mathrm{T}_{\mathrm{s}}$ is saturation temperature, $T_{1}$ is start boiling temperature. $T_{2}$ is finish boiling temperature, $\tau$ is time in sec, $\tau_{n b}$ is duration of transient nucleate boiling process in sec, $\mathrm{R}$ is radius in $\mathrm{m}$, .D is diameter or thickness of plate, $\mathrm{a}$ is thermal diffusivity in $\mathrm{m}^{2} / \mathrm{s}, \lambda$ is thermal conductivity of material in $\mathrm{W} / \mathrm{m} \mathrm{K}$, $\alpha_{\text {conv }}$ is convective heat transfer coefficient in $\mathrm{W} / \mathrm{m}^{2} \mathrm{~K}, \beta=3.41, \mathrm{~m}=10 / 3, \mathrm{~K}$ is Kondratjev form factor in $\mathrm{m}^{2}$, $\mathrm{c}$ is specific heat capacity, $\rho$ is density, $\mathrm{q}_{\mathrm{nb}}$ is heat flux density at the end of transient nucleate boiling process, $\mathrm{q}_{\text {conv }}$ is heat flux density at the beginning of convection, $\mathrm{k}=1,2,3$ for plate, cylinder and sphere correspondently, $\mathrm{Kn}$ is dimensionless Kondratjev number, Fo is dimensionless Fourier number.

\section{The self-regulated thermal process}

The self-regulated thermal process is transient nucleate boiling taking place during quenching [6]. During the self-regulated thermal process the surface temperature of steel parts maintains at the level of boiling point of liquid and never can be below it until boiling heat transfer coefficient is larger than convection heat transfer coefficient [6]. There are two specific surface temperatures of self-regulated thermal process (SRTP): $\mathrm{T}_{1}$ and $\mathrm{T}_{2}$.Within the short time interval between temperatures $\mathrm{T}_{\mathrm{o}}$ and $\mathrm{T}_{1}$ (Fig. 1) the formation of boiling boundary layer is formed. Cold liquid is heated to boiling point and surface temperature of steel parts drops immediately to temperature $\mathrm{T}_{1}$. At the temperature $T_{1}$ developed transient nucleate boiling process starts which continue until temperature $\mathrm{T}_{2}$ is reached. Duration of transient nucleate boiling process or SRTP was investigated by author [5, 6]. SRTP was used to perform austempering in cold liquids [7] that extends sizes of steel parts suitable for austempering and increases cooling rate during performing new technology. 
SRP can be used also for low temperature thermo-mechanical treatment of steels to receive super strengthened materials.

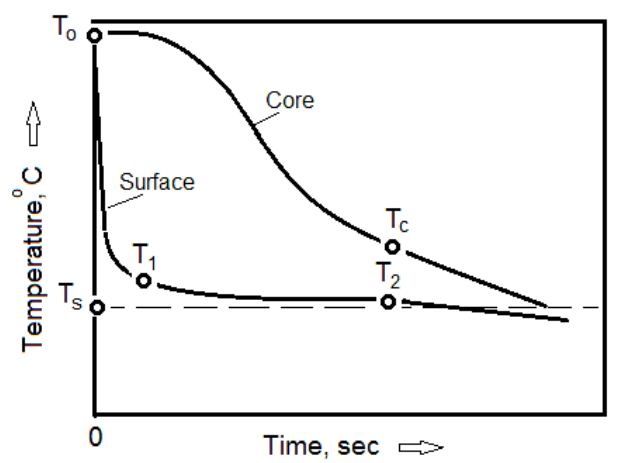

Fig. 1. A scheme showing the main characteristics of self-regulated thermal process: $\mathrm{T}_{\mathrm{S}}$ is saturation temperature; $\mathrm{T}_{1}$ is start temperature of transient nucleate boiling process;

$\mathrm{T}_{2}$ is temperature where convection starts and nucleate boiling switches to convection

Since during self-regulated thermal process surface temperature of steel parts changes insignificantly, the first type of boundary condition can be used for calculating core temperature at the end of transient nucleate boiling process. In this case the surface temperature during nucleate boiling process is considered as $\overline{\mathrm{T}}_{\mathrm{sf}}=\left(\mathrm{T}_{1}+\mathrm{T}_{2}\right) / 2$ (Fig. 1).

The values of $\mathrm{T}_{1}$ and $\mathrm{T}_{2}$ temperatures are presented in Table 1, 2 .

Table 1

Self-regulated start temperature in ${ }^{\circ} \mathrm{C}$ at the surface of steel parts depending on their sizes

\begin{tabular}{ccc}
\hline $\mathbf{D}, \mathbf{m m}$ & $\mathbf{T}_{\mathbf{1}},{ }^{\circ} \mathbf{C}$ \\
\hline 12.5 & 130 \\
20 & 126 \\
30 & 123 \\
40 & 122 \\
50 & 120 \\
60 & 119 \\
80 & 117 \\
100 & 116
\end{tabular}

Table 2

Self-regulated finish temperature in ${ }^{\circ} \mathrm{C}$ at the surface of steel parts depending on convective heat transfer coefficients

\begin{tabular}{ccc}
\hline $\boldsymbol{\alpha}_{\text {conv }}, \mathbf{W} / \mathbf{m}^{2} \mathbf{K}$ & $\mathbf{T}_{2},{ }^{\circ} \mathbf{C}$ \\
\hline 750 & 108 \\
1500 & 110 \\
2000 & 111 \\
3000 & 113 \\
4000 & 114 \\
5000 & 115
\end{tabular}

The data presented in Table 1, 2 were used for simplified calculations discussed below. 


\section{Simplified method for main characteristics of transient nucleate boiling evaluation}

Duration of transient nucleate boiling process is evaluated from Eq. (6) and average surface temperature from Table 1, 2. Analytical solutions for temperature fields evaluation in plate, cylinder and sphere at first type of boundary condition was provided by author [4, 8] (Eq. (7)-(9)).

Solution for plate is

$$
\theta=\frac{T(x, \tau)-T_{m}}{T_{0}-T_{m}}=\sum_{n-1}^{\infty} \frac{2}{\mu_{n}}(-1)^{n+1} \cos \mu_{n} \frac{x}{R} \exp \left(-\mu_{n}^{2} F o\right),
$$

here

$$
\mu_{\mathrm{n}}=(2 \mathrm{n}-1) \frac{\pi}{2} ; \mu_{1}=1.5708 ; \quad \mu_{2}=4.71 ; \mu_{3}=7.85 ; \frac{2}{\mu_{1}}=1.273 \text {. }
$$

Solution for cylinder is:

$$
\theta=\frac{T(r, \tau)-T_{m}}{T_{0}-T_{m}}=\sum_{n-1}^{\infty} A_{n} J\left(\mu_{n} \frac{r}{R}\right) \exp \left(-\mu_{n}^{2} F o\right)
$$

here

$$
A_{n}=\frac{2}{\mu_{n} J_{1}\left(\mu_{n}\right)}, \mu_{1}=2.4048 ; \mu_{2}=5.5201
$$

Solution for sphere is:

$$
\begin{aligned}
\theta=\frac{T(r, \tau)-T_{m}}{T_{0}-T_{m}} & =\sum_{n-1}^{\infty} A_{n} \frac{R \sin \mu_{n} \frac{r}{R}}{r \mu_{n}} \exp \left(-\mu_{n}^{2} F o\right), \\
A_{n} & =(-1)^{n+1} \times 2 ; \mu_{n}=n \pi .
\end{aligned}
$$

Mentioned above solutions were used for core temperature evaluation at the end of transient nucleate boiling process. For this purpose the dimensionless temperature in Eq. (7)-(9) was considered as

$$
\theta=\frac{\mathrm{T}_{\mathrm{c}}-\left(\mathrm{T}_{1}+\mathrm{T}_{2}\right) / 2}{\mathrm{~T}_{0}-\left(\mathrm{T}_{1}+\mathrm{T}_{2}\right) / 2}
$$

The duration of transient nucleate boiling process for any form of steel part was calculated from generalized Eq. (6). That was enough information to get accurate data on core temperature at the end of transient nucleate boiling process (Table 3).

Using core temperature at the end of transient nucleate boiling process (Table 3) and generalized Eq. (10), it is possible to calculate effective Kondratjev number Kn [8] needed for evaluation any core temperature during all process of cooling.

$$
\tau=\left[0.24 \mathrm{k}+\ln \frac{\mathrm{T}_{0}-\mathrm{T}_{\mathrm{m}}}{\mathrm{T}-\mathrm{T}_{\mathrm{m}}}\right] \frac{\mathrm{K}}{\mathrm{aKn}} .
$$

Effective number Kn can be easily calculated by equalizing Eq. (6) and Eq. (10), i. e.

$$
\left[0.24 \mathrm{k}+3.21 \ln \frac{\vartheta_{\mathrm{I}}}{\vartheta_{\text {II }}}\right]=\left[0.24 \mathrm{k}+\ln \frac{\mathrm{T}_{0}-\mathrm{T}_{\mathrm{m}}}{\mathrm{T}_{\text {core }}-\mathrm{T}_{\mathrm{m}}}\right] \frac{1}{\mathrm{Kn}} .
$$


Table 3

Core temperature $\left({ }^{\circ} \mathrm{C}\right)$ at the end of SRTP versus size of different form samples in mm and convection cooling intensity in $\mathrm{W} / \mathrm{m}^{2} \mathrm{~K}$

\begin{tabular}{|c|c|c|c|c|c|c|c|c|}
\hline \multicolumn{9}{|c|}{$750 \mathrm{~W} / \mathrm{m}^{2} \mathrm{~K}$} \\
\hline Size & 12.5 & 20 & 30 & 40 & 50 & 60 & 80 & 100 \\
\hline Plate & 130 & 136 & 143 & 150 & 156 & 169 & 181 & 194 \\
\hline Cylinder & 130 & 136 & 142.5 & 149 & 155.5 & 168 & 180 & 193.5 \\
\hline Sphere & 130 & 136 & 142 & 149 & 155 & 168 & 180 & 193 \\
\hline \multicolumn{9}{|c|}{1500} \\
\hline Size & 12.5 & 20 & 30 & 40 & 50 & 60 & 80 & 100 \\
\hline Plate & 142 & 154 & 166 & 180 & 198 & 224 & 251 & 278 \\
\hline Cylinder & 142 & 148 & 165 & 180 & 197 & 222 & 249 & 275 \\
\hline Sphere & 142 & 147 & 164 & 180 & 196 & 220 & 247 & 273 \\
\hline \multicolumn{9}{|c|}{2000} \\
\hline Size & 12.5 & 20 & 30 & 40 & 50 & 60 & 80 & 100 \\
\hline Plate & 150 & 164 & 185 & 205 & 225 & 246 & 287 & 328 \\
\hline Cylinder & 146 & 163 & 182 & 203 & 223.6 & 244 & 284 & 324 \\
\hline Sphere & 143 & 162.6 & 183 & 202.5 & 222 & 242 & 282 & 320 \\
\hline \multicolumn{9}{|c|}{3000} \\
\hline Size & 12.5 & 20 & 30 & 40 & 50 & 60 & 80 & 100 \\
\hline Plate & 175 & 202 & 224 & 249 & 288 & 316 & 376 & 453 \\
\hline Cylinder & 169 & 192 & 226 & 245 & 279 & 313 & 374 & 443 \\
\hline Sphere & 170 & 185 & 214 & 242 & 276 & 310 & 372 & 430 \\
\hline \multicolumn{9}{|c|}{4000} \\
\hline Size & 12.5 & 20 & 30 & 40 & 50 & 60 & 80 & 100 \\
\hline Plate & 180 & 212 & 258 & 297 & 337 & 380 & 461 & 550 \\
\hline Cylinder & 180 & 211 & 255 & 295 & 335 & 377 & 456 & 544 \\
\hline Sphere & 179 & 209 & 251 & 292 & 332 & 375 & 451 & 538 \\
\hline \multicolumn{9}{|c|}{5000} \\
\hline Size & 12.5 & 20 & 30 & 40 & 50 & 60 & 80 & 100 \\
\hline Plate & 180 & 212 & 258 & 297 & 337 & 380 & 461 & 550 \\
\hline Cylinder & 180 & 211 & 255 & 295 & 335 & 377 & 456 & 544 \\
\hline Sphere & 179 & 209 & 251 & 292 & 332 & 375 & 451 & 538 \\
\hline
\end{tabular}

In Eq. (11) $\mathrm{T}_{\text {core }}$ is taken from Table 3. Index $\mathrm{k}$ depends on form of steel part and can be evaluated from the Table 4. 
Table 4

Coefficient $\mathrm{k}$ depends on form of steel part and is evaluated knowing ratio of dimensions

\begin{tabular}{ccc}
\hline Size & $\mathbf{k}$ \\
$\mathrm{L}_{2}=\mathrm{L}_{3}=4 \mathrm{~L}_{1}$ \\
$4 \mathrm{Z}=\mathrm{D}$ \\
$\mathrm{L}_{2}=2 \mathrm{~L}_{1}$ \\
$\mathrm{~L}_{3}=4 \mathrm{~L}_{1}$ \\
$\mathrm{Z}=2 \mathrm{D}$ \\
$\mathrm{L}_{1}=\mathrm{L}_{2}=\mathrm{L}_{3} / 4$ \\
$\mathrm{Z}=4 \mathrm{D}$ \\
$\mathrm{Z}=1.5 \mathrm{D}$ \\
$\mathrm{L}_{2}=\mathrm{L}_{3}=1.5 \mathrm{~L}_{1}$ \\
$\mathrm{~L}_{1}=\mathrm{L}_{2}=\mathrm{L}_{3}$ \\
$\mathrm{Z}=\mathrm{D}$
\end{tabular}

Thus, simplified method of calculation investigates transient nucleate boiling process in detail which takes place during quenching in liquid media.

\section{Research results}

The transient nucleate boiling process was investigated widely and deeply by authors [3, 5-7]. In current investigation, it has been established a linear function of core temperature at the end of transient nucleate boiling process versus size of plate, cylinder and sphere. It appeared that form of sample doesn't affect core temperature (Fig. 2).

Moreover, the established function, at fixed convective HTC equal $4000 \mathrm{~W} / \mathrm{m}^{2} \mathrm{~K}$, can be written as:

$$
\mathrm{T}=128+4.2 \mathrm{D}
$$

When temperature in Eq. (12) approaches $850^{\circ} \mathrm{C}$ direct convection starts. It means that direct convection takes place when diameter of samples is $172 \mathrm{~mm}$ that satisfies Eq. (12). Conventional Biot number $\mathrm{Bi}$ at this point is

$$
\mathrm{Bi}=\frac{4000 \mathrm{~W} / \mathrm{m}^{2} \mathrm{~K}}{22 \mathrm{~W} / \mathrm{mK}} \times 0.086 \mathrm{~m}=15.64
$$

On the other hand, direct convection is evaluated by criterion [2]:

$$
\begin{gathered}
\mathrm{Bi}=\frac{2\left(\vartheta_{0}-\vartheta_{\mathrm{I}}\right)}{\vartheta_{\mathrm{I}}+\vartheta_{\mathrm{uh}}}=\frac{2(750-13.4)}{13.4+80}=15.77 \\
\vartheta_{\mathrm{I}}=\frac{1}{\beta}\left[\frac{2 \lambda\left(\vartheta_{0}-\vartheta_{\mathrm{I}}\right)}{\mathrm{R}}\right]^{0.3}=\frac{1}{3.41}\left[\frac{44(750-15)}{0.086}\right]^{0.3}=13.4^{\circ} \mathrm{C} .
\end{gathered}
$$

Difference between two methods of calculation is

$$
\varepsilon=\frac{17.77-15.64}{15.77} \times 100 \%=0.8 \%
$$

It means that our calculations are very accurate and realistic. 


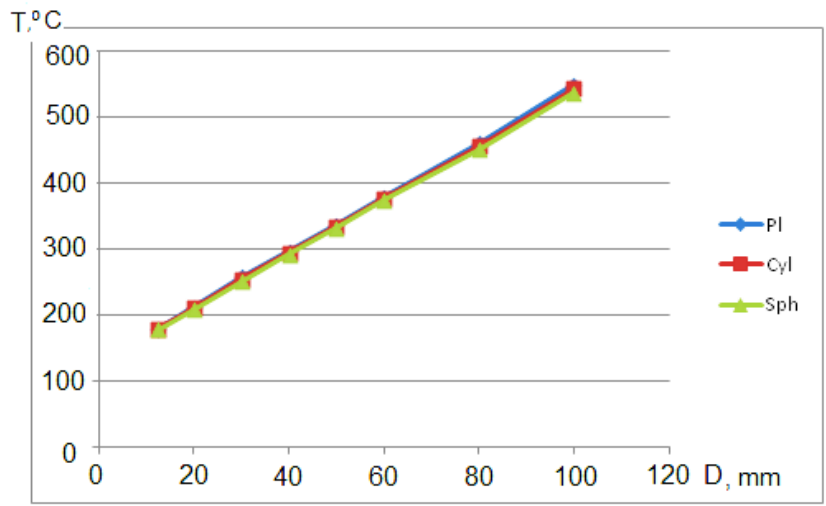

Fig. 2. Core temperature at the end of transient nucleate boiling process versus size of plate (Pl), cylinder (Cyl) and sphere (Sph) when convective heat transfer coefficient is $4000 \mathrm{~W} / \mathrm{m}^{2} \mathrm{~K}$

As seen from Fig. 3, effective Kondratjev number Kn insignificantly depends on forms and sizes of samples. Beginning from $30 \mathrm{~mm}$ diameter, linear function is observed between $\mathrm{Kn}$ and $\mathrm{D}$. That creates possibility to make generalization regarding effective Kondratjev numbers Kn.

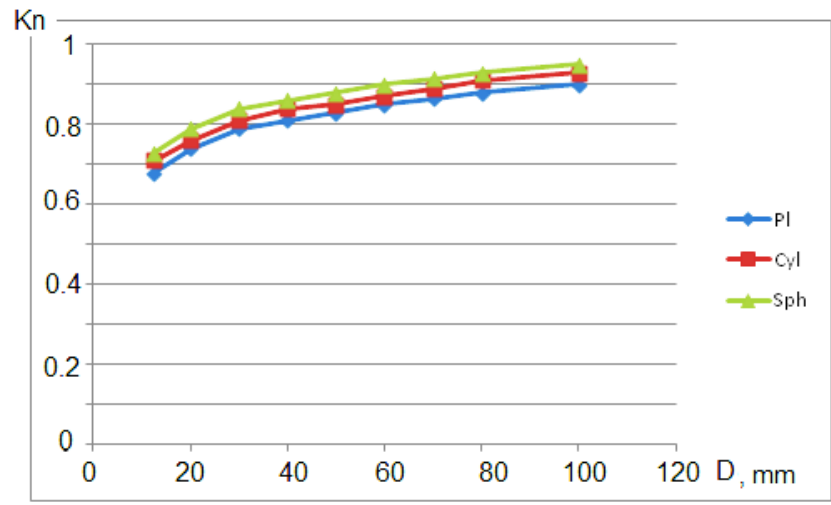

Fig. 3. Effective number Kn versus size of plate (Pl), cylinder (Cyl) and sphere (Sph) when convective heat transfer coefficient is $4000 \mathrm{~W} / \mathrm{m}^{2} \mathrm{~K}$

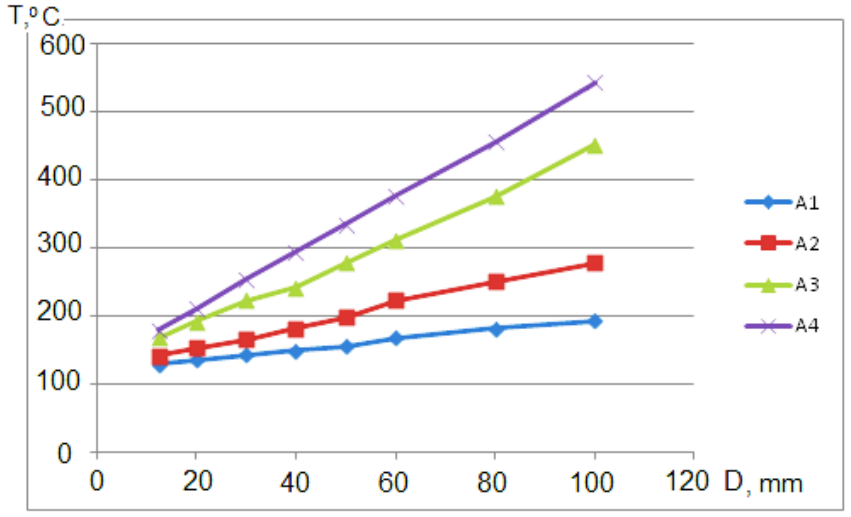

Fig. 4. Core temperature at the end of self-regulated thermal process versus size in $\mathrm{mm}$ of cylinder when convective heat transfer coefficient is $750 \mathrm{~W} / \mathrm{m}^{2} \mathrm{~K}$ (A1); $1500 \mathrm{~W} / \mathrm{m}^{2} \mathrm{~K}$ (A2); $3000 \mathrm{~W} / \mathrm{m}^{2} \mathrm{~K}(\mathrm{~A} 3)$; and $4000 \mathrm{~W} / \mathrm{m}^{2} \mathrm{~K}$ (A4)

Both core temperature at the end of transient nucleate boiling process and effective Kondratjev number Kn depend significantly on heat transfer coefficient during convection (Fig. 4, 5 and Table 3, 5). 


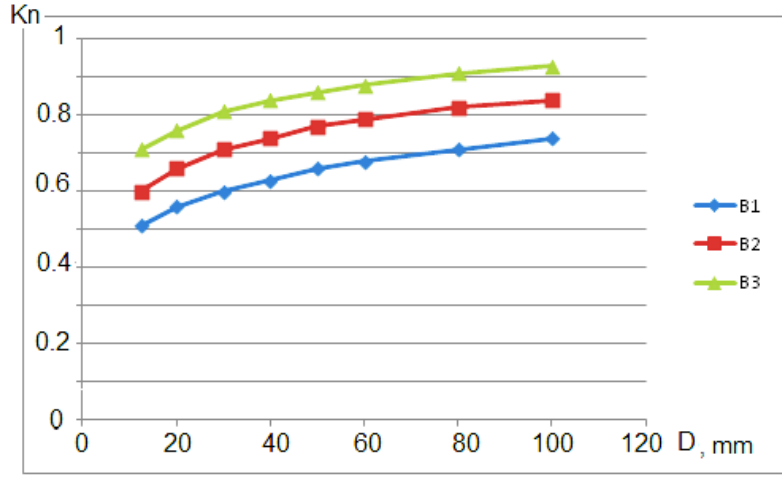

Fig. 5. Effective number Kn versus size of cylinders for different convective heat transfer coefficients: $\mathrm{B} 1$ is $750 \mathrm{~W} / \mathrm{m}^{2} \mathrm{~K}$; $\mathrm{B} 2$ is $1500 \mathrm{~W} / \mathrm{m}^{2} \mathrm{~K}$; $\mathrm{B} 3$ is $4000 \mathrm{~W} / \mathrm{m}^{2} \mathrm{~K}$

Table 5

Effective Kondratjev numbers $\mathrm{Kn}$ versus size of different form samples in $\mathrm{mm}$ and convection intensity of cooling in $\mathrm{W} / \mathrm{m}^{2} \mathrm{~K}$

\begin{tabular}{|c|c|c|c|c|c|c|c|c|}
\hline \multicolumn{9}{|c|}{$750 \mathrm{~W} / \mathrm{m}^{2} \mathrm{~K}$} \\
\hline Size & 12.5 & 20 & 30 & 40 & 50 & 60 & 80 & 100 \\
\hline Plate & 0.51 & 0.55 & 0.60 & 0.63 & 0.66 & 0.68 & 071 & 0.74 \\
\hline Cylinder & 0.53 & 0.58 & 0.63 & 0,65 & 0.68 & 0.71 & 0.74 & 0.77 \\
\hline Sphere & 0.56 & 0.60 & 0.65 & 0.675 & 0.70 & 0.73 & 0.76 & 0.79 \\
\hline \multicolumn{9}{|c|}{1500} \\
\hline Size & 12.5 & 20 & 30 & 40 & 50 & 60 & 80 & 100 \\
\hline Plate & 0.58 & 0.635 & 0.69 & 0.715 & 0.74 & 0.763 & 0.786 & 0.81 \\
\hline Cylinder & 0.60 & 0.66 & 0.72 & 0.74 & 0.76 & 0.786 & 0.813 & 0.84 \\
\hline Sphere & 0.63 & 0.69 & 0.74 & 0.76 & 0.78 & 0.806 & 0.833 & 0.86 \\
\hline \multicolumn{9}{|c|}{2000} \\
\hline Size & 12.5 & 20 & 30 & 40 & 50 & 60 & 80 & 100 \\
\hline Plate & 0.61 & 0.66 & 0.71 & 0.735 & 0.76 & 0.77 & 0.80 & 0.83 \\
\hline Cylinder & 0.62 & 0.665 & 0.735 & 0.76 & 0.785 & 0.795 & 0.825 & 0.855 \\
\hline Sphere & 0.63 & 0.67 & 0.76 & 0.79 & 0.81 & 0.82 & 0.85 & 0.88 \\
\hline \multicolumn{9}{|c|}{3000} \\
\hline Size & 12.5 & 20 & 30 & 40 & 50 & 60 & 80 & 100 \\
\hline Plate & 0.63 & 0.70 & 0.76 & 0.78 & 0.80 & 0.82 & 0.855 & 0.89 \\
\hline Cylinder & 0.65 & 0.77 & 0.82 & 0.83 & 0.865 & 0.86 & 0.88 & 0.93 \\
\hline Sphere & 0.67 & 0.78 & 0.83 & 0.85 & 0.88 & 0.90 & 0.93 & 0.96 \\
\hline \multicolumn{9}{|c|}{4000} \\
\hline Size & 12.5 & 20 & 30 & 40 & 50 & 60 & 80 & 100 \\
\hline Plate & 0.68 & 0.74 & 0.79 & 0.81 & 0.83 & 0.85 & 0.88 & 0.90 \\
\hline Cylinder & 0.71 & 0.76 & 0.81 & 0.84 & 0.85 & 0.875 & 0.91 & 0.93 \\
\hline Sphere & 0.73 & 0.79 & 0.84 & 0.86 & 0.88 & 0.90 & 0.93 & 0.95 \\
\hline \multicolumn{9}{|c|}{5000} \\
\hline Size & 12.5 & 20 & 30 & 40 & 50 & 60 & 80 & 100 \\
\hline Plate & 0.77 & 0.80 & 0.82 & 0.84 & 0.86 & 0.88 & 0.90 & 0.90 \\
\hline Cylinder & 0.77 & 0.815 & 0.825 & 0.86 & 0.89 & 0.905 & 0.92 & 0.93 \\
\hline Sphere & 0.78 & 0.82 & 0.83 & 0.875 & 0.91 & 0.925 & 0.94 & 0.95 \\
\hline
\end{tabular}

It means that special attention should be paid to convective HTCs during recipes development and software designing. 


\section{Discussion}

The steady-state boiling processes were investigated by many authors [9-11]. Transient nucleate boiling processes are not enough investigated yet. In heat treating industry, including big companies like DOW, are widely used only cooling curves and cooling rate data obtained by testing Inconel 600 probe [12-15]. These data can be used only for comparison reason to see how much new liquid quenchant differs from already existing, for example oil, and keep in shops cooling intensity of coolants at the same level. Unfortunately, it is impossible to use cooling curves and cooling rates for computer simulation and developing cooling recipes of real steel parts. As a result, customizers face some problems connected with distortion issues because in many cases cooling should be interrupted at proper time to prevent non-uniformity of cooling during quenching as shown Fig. 6 [16, 17]. A methodology is developed for testing liquid media as a quenchant and results of testing can be successfully used for recipes development. Methodology of calculation can be combined with recording of boiling signals during quenching that provides high quality of controlling the technological processes. Investigations on recording boiling signal during quenching are widely discussed in Refs [18, 19-21].

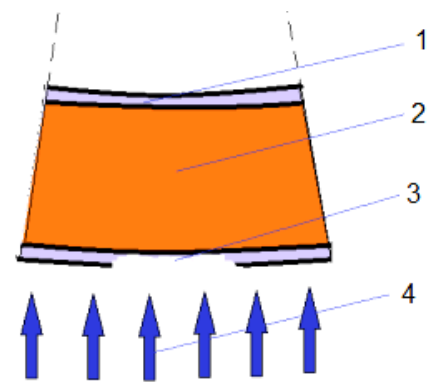

Fig. 6. A scheme explaining why a big distortion takes place during quenching in water PAG polymer solutions caused by dissolving polymeric surface layer

(Source: N. I. Kobasko, EUREKA: Physics and Engineering, 2017, No. 2, page 59):

1 - polymer coating; 2 - quenched steel part; 3 - locally dissolved by water flow polymer coating that provides non-uniform cooling; 4 - water flow

Also, author of the paper suggests using Inconel 600 probe combined with the Liscic/ Petrofer probe to develop DATABASE for liquid quenchant to be used for computer simulation and recipes development.

\section{Conclusions}

1. The main characteristics of self-regulated thermal process are:

- duration of SRTP;

- core temperature at the end of transient nucleate boiling process;

- start surface self-regulation temperature and surface finish temperature of steel parts used for creation the first type of boundary condition;

- average surface temperature during SRTP;

- Effective Kondratjev number Kn within the transient nucleate boiling process.

2. Core temperature of steel parts at the end of transient nucleate boiling process is a linear function the size of product and doesn't depend on its form.

3. Effective Kondratjev number Kn changes insignificantly with the change of size of steel part and is a linear function of size for large dimensions. This allows using Inconel 600 probe combined with the Liscic/Petrofer probe for DATABASE designing to be widely applied to heat treating industry needs and software development.

4. Probability of quench cracks formation can be completely eliminated and distortion can be minimized if obtained characteristics of self-regulated thermal process are correctly used for recipes development. 


\section{References}

[1] Liscic, B., Tensi, H. M., Luty, W. (Eds.) (1992). Theory and Technology of Quenching. Springer-Verlag, Berlin, New York, 484. doi: 10.1007/978-3-662-01596-4

[2] Kobasko, N., Aronov, M., Powell, J., Totten, G. (2010). Intensive Quenching Systems: Engineering and Design. ASTM International, West Conshohocken, 252. doi: 10.1520/mnl64-eb

[3] French, H. J. (1930). The Quenching of Steels. American Society for Steel Treating, Cleveland, $\mathrm{OH}, 177$.

[4] Lykov, A. V. (1967). Teoriya Teploprovodnosti [Theory of Heat Conductivity]. Moscow: Vysshaya Shkola, 596.

[5] Kobasko, N. I. (1980). Steel Quenching in Liquid Media under Pressure. Kyiv: Naukova Dumka, 206.

[6] Kobasko, N. I. (2016). Self - regulated thermal process, its main characteristics and practical application. International Journal of Current Research, 8 (11), 41698-41704.

[7] Kobasko, N. I. (2013). Pat. No. 109935 UA. Method for isothermal hardening of product from high-alloyed steel or cast iron. MPK: C21D 1/19, C21D 1/20, C21D 1/18. No. a201313212; declareted: 13.11.2013; published: 26.10.2015, Bul. No. 20.

[8] Kondrat'ev, G. M. (1957). Thermal Measurements. Moscow: Mashgiz.

[9] Tolubinsky, V. I. (1980). Heat Transfer at Boiling. Kyiv: Naukova Dumka, 315.

[10] Kutateladze, S. S. (1963). Fundamentals of Heat Transfer. Academic Press, New York, 485.

[11] Labuntsov, D. A. (2000). Physical Fundamentals of Power Engineering: Selected Works on Heat Transfer. Hydrodynamics and Thermodynamics, MPEI, Moscow.

[12] Liščić, B. (2016). Measurement and Recording of Quenching Intensity in Workshop Conditions Based on Temperature Gradients. Materials Performance and Characterization, 5 (1), MPC20160007. doi: 10.1520/mpc20160007

[13] Test Method for Determination of Cooling Characteristics of Quench Oils by Cooling Curve Analysis. doi: 10.1520/d6200-01r12

[14] Test Method for Determination of Cooling Characteristics of Aqueous Polymer Quenchants by Cooling Curve Analysis with Agitation (Tensi Method). doi: 10.1520/d6482-06r16

[15] Test Method for Determination of Cooling Characteristics of Quenchants by Cooling Curve Analysis with Agitation (Drayton Unit). doi: 10.1520/d6549-06r15

[16] Kobasko, N. (2017). Cooling intensity of inverse solubility polyalkylene glykol polymers and some results of investigations focused on minimizing distortion of metal components. EUREKA: Physics and Engineering, 2, 55-62. doi: 10.21303/2461-4262.2017.00294

[17] Kobasko, N. (2016). Investigation of batch intensive quenching processes when using hydrodynamic emitters in quench tanks. EUREKA: Physics and Engineering, 6, 29-36. doi: 10.21303/24614262.2016.00212

[18] Ravnik, F., Grum, J. (2011). Heat Transfer Stages Recognition by Boiling Acoustic During Quenching. Journal of ASTM International, 8 (1), 1-13. doi: 10.1520/jai103386

[19] Grum, J., Božič, S. (2003). Acoustic Emission During Quenching of 42CrMo4 Steel. Fourth International Conference on Quenching and the Control of Distortion.

[20] Dorofeev, B. M., Volkova, V. I. (2005). An Acoustic Method of Investigation of the Process of Boiling. High Temperature, 43 (4), 620-627. doi: 10.1007/s10740-005-0104-6

[21] Ganiev, R. F., Ukrainskiy, L. E. (2012). Nonlinear Wave Mechanics and Technologies-Wave and Oscillatory Phenomena on the Basis of High Technologies. USA: Begell House, 527. 